\title{
Adjunct Clinical Trial
}

National Cancer Institute

\section{Source}

National Cancer Institute. Adjunct Clinical Trial. NCI Thesaurus. Code C18707.

A clinical trial that uses materials from some other clinical trial. 